\title{
Analisis Data E-Absensi untuk Menganalisis Perbandingan Pola Disiplin Kerja menggunakan Algoritma Clustering K-Means
}

\author{
${ }^{1}$ Reksa Suhud Tri Atmojo, ${ }^{2}$ Leady Pramudita, ${ }^{3}$ Heni Novita Sari, ${ }^{4}$ Bagus Arifudin, ${ }^{5}$ Gigih Forda Nama \\ ${ }^{1}$ Program Studi Teknik Informatika \\ Jurusan Teknik Elektro, Fakultas Teknik, Universitas Lampung \\ Jalan Soemantri Brojonegoro No.1, Bandar Lampung, 35141 \\ ${ }^{1}$ reksa.suhudtri1501estudents.unila.ac.id
}

Intisari - Data mining merupakan suatu proses untuk menemukan informasi-informasi yang bermanfaat dari sekumpulan basis data yang berukuran besar. Pada penelitian ini akan mengolah data yang ada pada sistem e-absensi menggunakan algoritma K-Means $\mathrm{K}=3$ menggunakan perangkat lunak Orange. Hasil penelitian ini menghasilkan hasil analisis pola perilaku kedisiplinan kerja dengan melihat presentase telat dan jumlah kehadiran yang diambil dari data E-Absensi SD Negeri X Taman Fajar Kecamatan Purbolinggo dan Puskesmas $Y$ yang berada di Desa Negara Nabung, Kabupaten Lampung Timur sehingga dapat menjadi pertimbangan bagi instansi terkait peningkatan tingkat kedisiplunan kerja. Dari penelitian, ini didapatkan kesimpulan pada clustering $\mathrm{C}$, $\mathrm{C2}$, dan $\mathrm{C3}$ dapat disimpulkan tingkat kedisiplinan kerja pada saat Bulan Ramadhan 1438 H yang jatuh pada bulan Juli 2018 di pegawai Puskesmas $Y$ lebih tinggi dibandingkan dengan pegawai SDN X Taman Fajar dari segi jumlah kehadiran, namun jika dilihat dari tingkat kedisiplinan dalam aspek presentase telat, Pegawai SDN $\mathbf{X}$ Taman Fajar lebih rendah dibanding pegawai Puskesmas Y .

Kata Kunci - Clustering, K-Means, Algoritma, E-Absensi, Pegawai

Abstract - Data mining is a process for finding useful information from a large collection of databases. In this study, we will process the data in the e-attendance system using the K-Means $K=3$ algorithm using Orange software. The results of this study resulted in the analysis of patterns of work discipline behavior by looking at the late percentage and number of attendance taken from the data of Time Attendance at SD Negeri X Taman Fajar in Purbolinggo Subdistrict and Y Public Health Center in Negara Nabung Village, East Lampung Regency so that it could be considered by agencies related to an increase in the level of employment discipline. From this research, it can be concluded that clustering $\mathrm{C} 1, \mathrm{C} 2$, and $\mathrm{C} 3$ can be concluded that the level of work discipline at the time of Ramadhan $1438 \mathrm{H}$ which falls in July 2018 at Y Public Health Center employees is higher than SDN X Taman Fajar employees in terms of attendance, but when viewed from the level of discipline in the late percentage aspect, SDN X Taman Fajar employees are lower than Y Puskesmas employees.

Keywords - Clustering, K-Means, Algorithm, E-Absensi, Employee

\section{PENDAHULUAN}

Setiap organisasi menginginkan pegawainya dapat bekerja secara maksimal mempengaruhi kinerja seorang pegawai, seperti umur, jenis kelamin, absensi. Absensi itu sendiri ialah tingkat kehadiran pegawai yang berkenaan dengan tanggung jawab. Kehadiran berkenaan dengan tanggung jawab pegawai saat bekerja, pegawai yang hadir tepat waktu, tidak terlambat dan tidak sering izin saat masuk kerja bisa dikatakan mempunyai sifat disiplin. Dalam rangka meningkatkan penertiban administrasi kepegawaian khususnya pencatatan kehadiran pegawai dinas di Lampung Timur, setiap Pegawai Negeri Sipil harus masuk kerja dan menaati jam kerja. 
Metode K-Means digunakan untuk mengelompokan absensi pegawai per bulan, Banyaknya jumlah transaksi absensi Pegawai Negeri Sipil yang dihasilkan dengan keterangan absensi masuk saja, absensi pulang saja, sering cuti dan sakit dapat dikelompokan menggunakan metode $\mathrm{K}$ Means dengan menggunakan perangkat lunak pengolah data mining yang bernama Orange. Hasil penelitian ini menghasilkan hasil analisis pola perilaku kedisiplinan kerja dengan melihat presentase telat dan jumlah kehadiran yang diambil dari data E-Absensi SD Negeri X Taman Fajar Kec. Purbolinggo dan Puskesmas $\mathrm{Y}$ yang berada di Desa Negara Nabung, Kabupaten Lampung Timur.

\section{TINJAUAN PUSTAKA}

\section{A. Pengertian Data Mining}

Tan (2006) mendefinisikan data mining sebagai proses untuk mendapatkan informasi yang berguna dari gudang basis data yang besar. Data mining juga dapat diartikan sebagai pengekstrakan informasi baru yang diambil dari bongkahan data besar yang membantu dalam pengambilan keputusan. Istilah data mining kadang disebut juga knowledge discovery. Salah satu teknik yang dibuat dalam data mining adalah adalah bagaimanana menelusuri data yang ada untuk membangun sebuah model, kemudian menggunakan model tersebut agar dapat mengenali pola data yang lain yang tidak berada dalam basis data yang tersimpan. Kebutuhan untuk prediksi juga dapat memanfaatkan teknik ini. Dalam data mining, pengelompokan data juga bisa dilakukan. Tujuannya adalah agar kita dapat mengetahui pola universal data-data yang ada. Anomali data transaksi juga perlu dideteksi untuk dapat mengetahui tindak lanjut berikutnya yang dapat diambil [1].

\section{B. Pengertian $K$-Means}

Merupakan mengelompokan data dalam bentuk satu atau lebih cluster/kelompok. Data-data yang memiliki karakteristik yang sama dikelompokan dalam satu cluster/kelompok dan data yang memiliki karakteristik yang berbeda dikelompokan dengan cluster/kelompok yang lain sehingga data yang berada dalam satu cluster/kelompok memiliki tingkat variasi yang kecil. Menurut Santosa (2007), langkahlangkah melakukan clustering dengan metode $K$-Means adalah sebagai berikut:

- Pilih jumlah cluster $k$.

- Inisialisasi $k$ pusat cluster ini bisa dilakukan dengan berbagai cara. Namun yang paling sering dilakukan adalah dengan cara random. Pusat-pusat cluster diberi nilai awal dengan angka-angka random,

- Alokasikan semua data/ objek ke cluster terdekat. Kedekatan dua objek ditentukan berdasarkan jarak kedua objek tersebut. Demikian juga kedekatan suatu data ke cluster tertentu ditentukan jarak antara data dengan pusat cluster. Dalam tahap ini perlu dihitung jarak tiap data ke tiap pusat cluster. Jarak paling antara satu data dengan satu cluster tertentu akan menentukan suatu data masuk dalam cluster mana. Untuk menghiutng jarak semua data ke setiap tiitk pusat cluster dapat menggunakan teori jarak Euclidean yang dirumuskan sebagai

berikut:

$$
\begin{aligned}
& D(i, j)=\sqrt{\left(X_{1 i}-X_{1 j}\right)^{2}+\left(X_{2 i}-X_{2 i}\right)^{2}+\cdots+\left(X_{k i}-X_{k j}\right)^{2}} \cdots(1) \\
& \text { dimana: } \\
& D \text { (i,j) }=\text { Jarak data ke } i \text { ke pusat cluster } j \\
& X_{k i}=\text { Data ke i i pada atribut data ke } k \\
& X_{k j}=\text { Titik pusat ke j pada atribut ke } k
\end{aligned}
$$

- Hitung kembali pusat cluster dengan keanggotaan cluster yang sekarang. Pusat cluster adalah rata-rata dari semua data/ objek dalam cluster tertentu. Jika dikehendaki bisa juga menggunakan median dari cluster tersebut. Jadi rata-rata (mean) bukan satu-satunya ukuran yang bisa dipakai.

- Tugaskan lagi setiap objek memakai pusat cluster yang baru. Jika pusat cluster tidak berubah lagi maka proses clustering selesai. Atau, kembali ke langkah nomor 3 sampai pusat cluster tidak berubah lagi [2]. 


\section{METODOLOGI PENELITIAN}

\section{A. Melakukan Preprocessing Data}

Dikarenakan data yang diperoleh dari EAbsensi Lampung Timur dalam bentuk database SQL maka perlu dilakukan normalisasi join table agar data yang diperoleh mudah untuk diolah. Berikut adalah struktur database aplikasi E-Absensi yang dianalisis

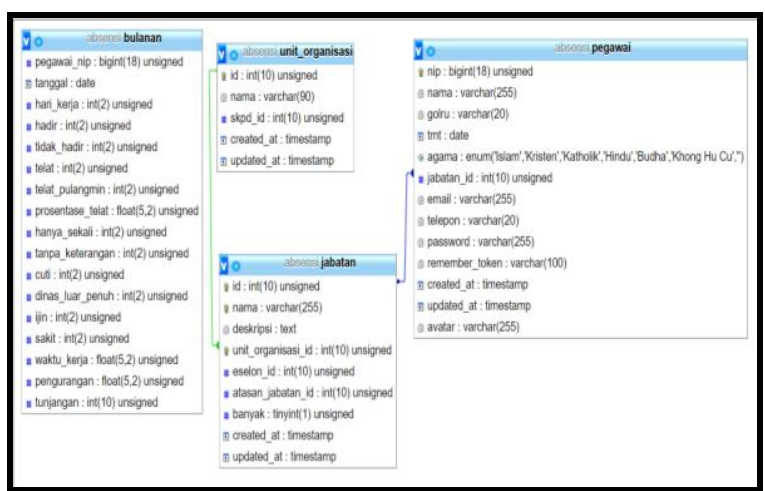

Gbr 1. Struktur relasi database sistem e-absensi kepegawaian Kabupaten Lampung Timur

Selanjutnya, melakukan filtering data menggunakan query SQL karena data SD Negeri X Taman Fajar Kec. Purbolinggo dan Puskesmas $Y$ yang berada di Desa Negara Nabung, Kabupaten Lampung Timur yang ingin dianalisa.

"SELECT pegawai.`nama`AS

nama_pegawai, unit_organisasi.`nama`AS

nama_instansi,

bulanan.`prosentase_telat`AS

presentase_telat, bulanan.'`hadir',

bulanan. 'tidak_hadir'

FROM pegawai JOIN bulanan ON

bulanan.`pegawai_nip`=pegawai.`nip`

JOIN jabatan ON

jabatan.`id`=pegawai.`jabatan_id

JOIN unit_organisasi ON

unit_organisasi.`id`=jabatan.`id` “

Berikut ini adalah hasil dari join tabel dengan query SQL :

Atribut yang akan dianalisis adalah nama, organisasi, presentase telat, hadir, dan tidak hadir. Dikarenakan yang dianalisis adalah kehadiran maka yang ditandai label adalah atribut hadir. Total record data salah satu
SDN dan Puskesmas di Kabupaten Lampung Timur yang akan diproses menggunakan KMeans Clustering pada penelitian ini ada 55 Record.

Tabel 1 Tabel hasil join

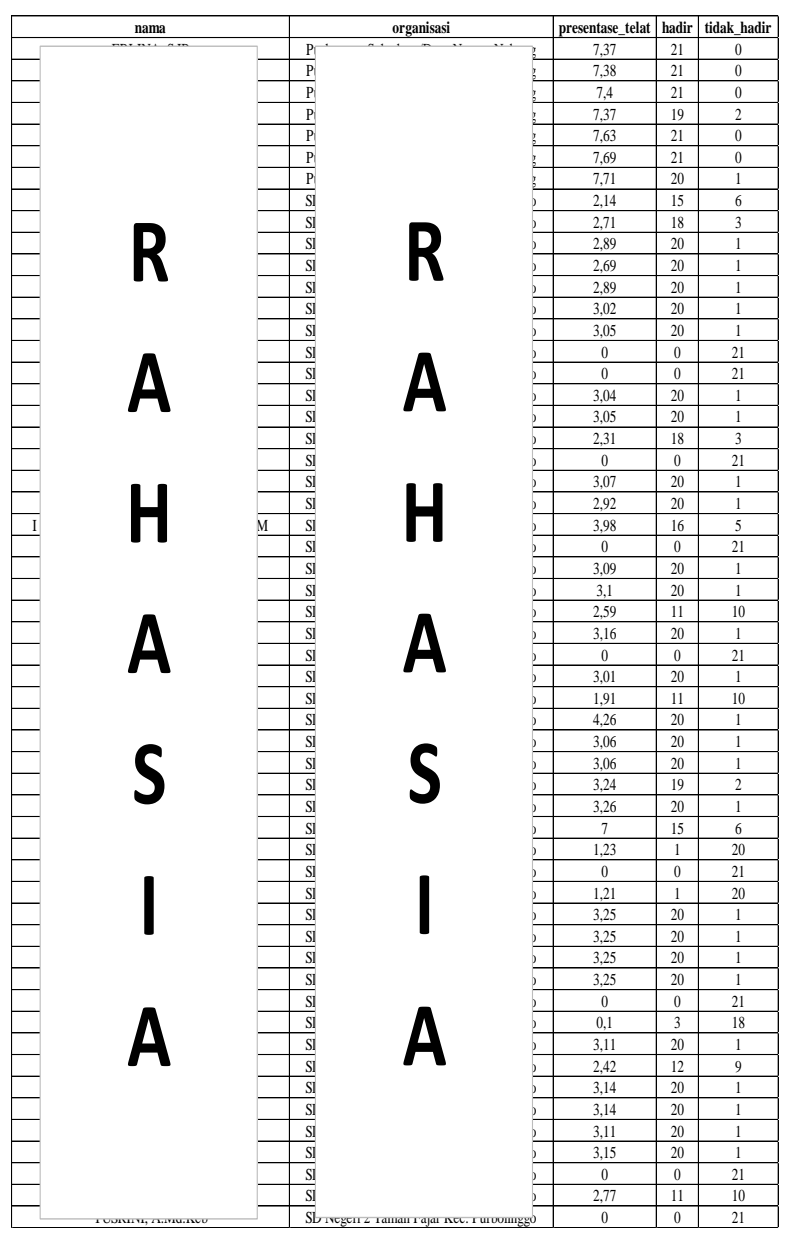

\section{B. Melakukan clustering K-Means}

Clustering K-Means bertujuan untuk melakukan clustering pada pegawai SD Negeri XTaman Fajar Kec. Purbolinggo dan Puskesmas Y yang berada di Desa Negara Nabung, Kabupaten Lampung Timur yang ingin dianalisa. Clustering yang kami gunakan adalah $\mathrm{K}=3$.

\section{Melakukan output data menggunakan penyajian data scatter plot}

Karena data yang diolah menggunakan algoritma K-Means dengan Clustering $\mathrm{K}=3$ dengan maximum iteration sebanyak 300 iterasi pada perangkat lunak orange. Maka 
akan menghasilkan data $\mathrm{C} 1, \mathrm{C} 2$, dan $\mathrm{C} 3$ yang akan disajikan menggunakan scatter plot. Secara garis besar berikut proses clustering yang dilakukan melalui canvas Orange

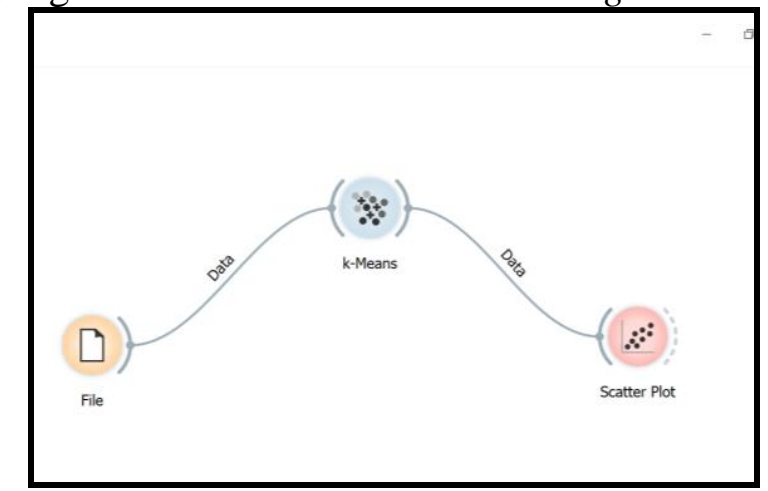

$\mathrm{Gb}$ 2. Struktur proses canvas clustering k-means pada perangkat lunak Orange

\section{PEMBAHASAN}

Setelah metode penelitian sudah dilakukan dan diolah melalui perangkat lunak Orange, didapatkan data yang sudah di sajikan melalui Scatter Plot.

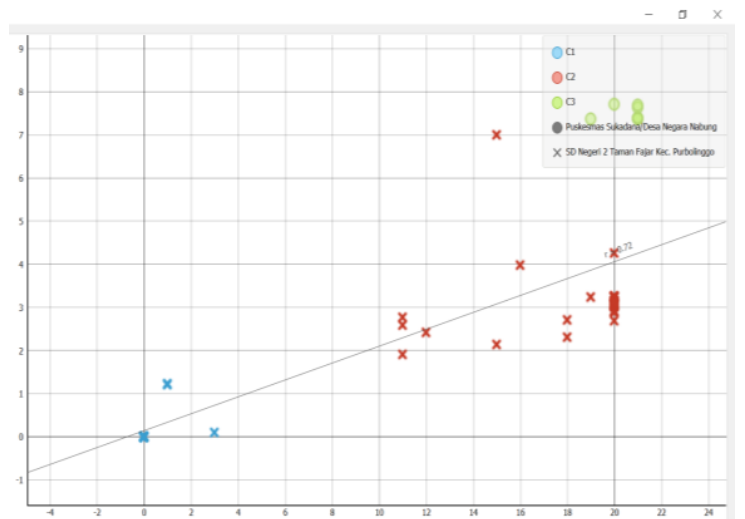

Gbr 3 . Hasi clustering K-Means yang disajikan dalam bentuk scatter plot

Pada Gambar 3 Sumbu X adalah data hadir dan Sumbu Y adalah data presentase telat hadir. Dari hasil pengolahan menggunakan Clustering didapatkan $\mathrm{C} 1, \mathrm{C} 2$, dan C3. C1 merupakan data pegawai yang memiliki intensitas kehadiran rendah dan presentase telat rendah. Clustering $\mathrm{C} 2$ diasumsikan sebagai pegawai yang memiliki intensitas kehadiran dan presentase telat rata- yang diasumsikan sebagai pegawai yang memiliki kehadiran rendah dan presentase telat rendah. rata. Sedangkan clustering C3 diasumsikan sebagai pegawai yang memiliki intensitas kehadiran tinggi dan presentase telat yang tinggi. Clustering $\mathrm{C} 1$ mayoritas datanya diisi oleh data pegawai SDN X Taman Fajar yang memiliki kehadiran rendah namun dengan presentase telat rendah pada saat bulan Ramadhan $1438 \mathrm{H}$ dengan centroid cluster $\mathrm{K}_{1}$ $=0,72$. Dapat disimpulkan hubungan adalah berbanding lurus, semakin rendah jumlah kehadiran maka semakin rendah presentase telat.Clustering $\mathrm{C} 2$ mayoritas datanya diisi oleh data pegawai SDN X Taman Fajar yang memiliki kehadiran rata-rata dan dengan presentase telat rata-rata pada absensi saat bulan Ramadhan $1438 \mathrm{H}$ dan centroid cluster $\mathrm{K}_{2}=0,79$. Dapat disimpulkan hubungan adalah berbanding lurus, semakin rendah jumlah kehadiran maka semakin rendah presentase telat. Clustering C3 mayoritas datanya diisi oleh data pegawai Puskesmas Y yang memiliki kehadiran tinggi namun dengan presentase telat yang tinggi pula pada saat bulan Ramadhan 1438H dengan centroid cluster $\mathrm{K}_{3}=0,767$. Dapat disimpulkan hubungan adalah berbanding lurus, semakin tinggi jumlah kehadiran maka semakin tinggi presentase telat.

Dari ketiga buah clustering $\mathrm{C} 1, \mathrm{C} 2$, dan $\mathrm{C} 3$ dapat disimpulkan tingkat kedisiplinan kerja pada saat Bulan Ramadhan $1438 \mathrm{H}$ yang jatuh pada bulan juli 2018 pada pegawai Puskesmas $\mathrm{Y}$ lebih tinggi dibandingkan dengan pegawai SDN X Taman Fajar dari segi jumlah kehadiran, namun jika dilihat dari tingkat kedisiplinan dalam aspek presentase telat, Pegawai SDN X Taman Fajar lebih rendah dibanding pegawai Puskesmas Sukadana.

Hal ini dapat menjadi pertimbangan pihak SDN X Taman Fajar mengapa tingkat kedisiplinan dilingkungan kerja SDN $\mathrm{X}$ Taman Fajar rendah, ataupun bisa jadi faktor lain, misalnya ada yang menyebabkan data kehadiran tidak tercatat di e-absensi dikarenakan kurangnya penyuluhan cara penggunaan system absensi.

\section{KESIMPULAN}

Dari hasil Penelitian didapatkan kesimpulan sebagai berikut :

- Metode data mining pada system eabsensi pada SDN X Taman Fajar dan Puskesmas $\mathrm{Y}$ menggunakan algoritma 
Clustering K-Means $\mathrm{K}=3$ dan menghasilkan cluster $\mathrm{C} 1, \mathrm{C} 2$, dan $\mathrm{C} 3$.

- Hubungan antara jumlah kehadiran dan presentase telat adalah berbanding lurus pada clustering C1, C2, dan C3. Dimana semakin tinggi jumlah kehadiran maka presentase telat juga berpotensi semakin tinggi, begitu juga sebaliknya

- Dari ketiga buah clustering $\mathrm{C} 1, \mathrm{C} 2$, dan C3 dapat disimpulkan tingkat kedisiplinan kerja pada saat Bulan Ramadhan $1438 \mathrm{H}$ pada pegawai Puskesmas $\mathrm{Y}$ lebih tinggi dibandingkan dengan pegawai SDN $\mathrm{X}$ Taman Fajar dari segi jumlah kehadiran, namun jika dilihat dari tingkat kedisiplinan dalam aspek presentase telat, Pegawai SDN X Taman Fajar lebih rendah dibanding pegawai Puskesmas Sukadana.

\section{REFERENSI}

[1] S. Haryati, A. Sudarsono, and E. Suryana, "Implementasi Data Mining Untuk Memprediksi Masa Studi Mahasiswa Menggunakan Algoritma C4.5 (Studi Kasus: Universitas Dehasen Bengkulu)," J. Media Infotama Vol., vol. 11, no. 2, pp. 130 138, 2015.

[2] J. O. Ong, "Implementasi Algotritma $\mathrm{K}$-means clustering untuk menentukan strategi marketing president university," J. Ilm. Tek. Ind., vol. vol.12, no, no. juni, pp. 10-20, 2013. 